\title{
SOSIALISASI PEREMPUAN SEBAGAI AGEN PEDULI LINGKUNGAN KEPADA GOW SEMARANG
}

\author{
Rustina Untari' ${ }^{1}$, Dhiyan Khrisna Wardhani², Mellia Harumi ${ }^{3}$, Kezia Yemima Aprilia ${ }^{4}$ \\ 1,2,3,4 Pusat Studi Wanita Unika Soegijapranata Semarang \\ r_untari@unika.ac.id
}

\begin{abstract}
Abtract: One of the parties who have great potential in environmental preservation efforts are women. Globally women provide a life for their families and at the same time manage the environment. However, due to gender power relations, their knowledge is often ignored, and they are not counted as agents of change. The Center for Women's Studies at Soegijapranata Catholic University seeks to improve the ability of women in terms of environmental preservation by organizing socialization of women as agents of environmental care to the Women's Organizations Association in Semarang City. The socialization was conducted with a participatory approach in which the participants are active in training and then also active in the development of eco-print products and efforts to disseminate environmental awareness. These outreach activities produce positive results that women have great potential as agents of change in the environmental care movement. in terms of the socialization process, in order to run well, the women's groups must have the potential to disseminate the results of socialization. The criteria for the women's group is to be able to represent the original group so that it can become the next media for socialization and be active on social media that is popular in the community, namely Instagram. Furthermore, this activity also found that training media as a means of socialization must be interesting, that is, easily made (done) by the trainees, the results are good so it is interesting to be seen and imitated by other parties, easy for replication, even trainees can immediately become trainers for other party
\end{abstract}

\section{Keyword: Women, Environmental Awareness, Gender, Agents Of Change, Ecoprint}

\section{PENDAHULUAN}

Lingkungan, sebagai tempat manusia dan organisme lain hidup berdampingan yang terdiri dari air, tanah, dan unsur kehidupan lain (Mahour, 2016) mengalami banyak perubahan dan dipaksa untuk menyesuaikan pola hidup manusia seiring dengan perubahan era dan bergantinya waktu. Sayangnya perubahan yang terjadi adalah penurunan mutu lingkungan. Sehingga perlu diupayakan perbaikan lingkungan atau usaha pelestariannya agar kelangsungan hidup manusia akan langgeng dalam jangka panjang dan manusia dapat hidup sejahtera dari waktu ke waktu.Salah satu pihak yang memiliki potensi besar dalam usaha pelestarian lingkungan hidup adalah perempuan. Secara global perempuan menyediakan kehidupan bagi keluarga mereka dan sekaligus mengelola lingkungan. Namun, karena hubungan kekuatan gender, pengetahuan mereka sering diabaikan dan mereka tidak diperhitungkan sebagai agen perubahan. Perempuan dan laki-laki Sebaiknya menjadi agen di lingkungan pengelolaan, termasuk sama partisipasi proses pembuatan keputusan dan kebijakan. (UNEP, 2015)

Sebagaimana disebutkan dalam alinea sebelumnya, adanya bias gender menyebabkan wanita pendapat perlakuan eksklusif termasuk dalam kegiatan pelestarian lingkungan hidup. Upaya peningkatan peran perempuan dalam pengelolaan lingkungan dapat dilakukan dengan peningkatan kapasitas misalnya dengan pelatihan yang terkait dengan Green Product terutama yang berhubungan dengan produk yang digunakan oleh masyarakat sehari hari (produk primer). Olah karena itu Pusat Studi Wanita kegiatan peningkatan kesadaran akan pengetahuan dan keterampilan perempuan akan pelestarian lingkungan. Terlepas dari terbatasnya akses yang dimiliki banyak perempuan ke pendidikan formal, mereka memiliki hak dan potensi khusus untuk berkontribusi pada 
masalah sosial dan ekologis daripada laki-laki, dan terkenal karena "kesadaran lingkungan" mereka yang lebih baik. (UNIDO, 2015)

Pusat Studi Wanita Unika Soegijapranta berusaha meningkatkan kemampuan perempuan dalam hal pelestarian lingkungan dengan cara mengadakan sosialisasi Perempuan sebagai Agen Perubahan Peduli Lingkungan kepada Gabungan Organisasi Wanita di Kota Semarang. Ecoprint dipilih sebagai sarana sosialisasi karena merupakan salah satu contoh produk tekstil yang ramah lingkungan. Pengetahuan dan ketrampilan akan tekstil ramah lingkungan diharapkan akan memicu perempuan peserta pelatihan memilih produk ramah lingkungan baik untuk diri sendiri atapun keluarganya dan selanjutnya menyebarluaskan kepada Gabungan Organisasi Wanita sebagai mitra pelatihan dengan tujuan akan menjadi wadah penyebarluasan pengetahuan dan semangat pelestarian lingungan hidup. Metode sosialisasi dilakukan dengan pendekatan partisipatif dimana para peserta aktif dalam pelatihan dan kemudian juga aktif dalam pengembangan produk ecoprint serta upaya penyebarluasannya. Kegiatan sosialisasi dilakukan bekerjasama berbagai pihak yaitu pemerintah, perguruan tinggi dan perusahaan swasta (termasuk UKM). Pihak pemerintah diwakili oleh Dinas Pemberdayaan Perempuan dan Anak Kota Semarang, pihak perguruan tinggi diwakili Pusat Studi Wanita Unika Soegijapranata Semarang. Pihak Swasta diwakili oleh Restoran Hoka Hoka Bento yang memiliki visi pada Kelestarian Lingkungan. Selain itu kegiatan pengabdian ini juga melibatkan UKM yaitu Batik Warna Alam Si Putri. Kerjasama model Triplehelix ini diharapkan akan memperlancar kegiatan dan memperluas dampak aktivitas pengabdian serta menjamin sustainabilitynya.

\section{METODE}

Permasalahan utama adalah perempuan seharusnya dapat berperan aktif dalam upaya pelestarian lingkungan hidup perlu bekal ilmu dan ketrampilan yang memadai. Terdapat tiga tahap dalam Pendakatan Penyelesaian Permasalahan diatas, yaitu memilih kelompok sasaran yang tepat, pelatihan untuk meningkatkan kemampuan kelompok sasaran tersebut dan Evaluasi serta monitoring untuk melihat apakah program penyebaruasan pengetahuan tentang Ecoproduct dan lingkungan hidup dapat berlangsung dengan baik. Ketiga tahap pendekatan seperti pada gambar 1 berikut.

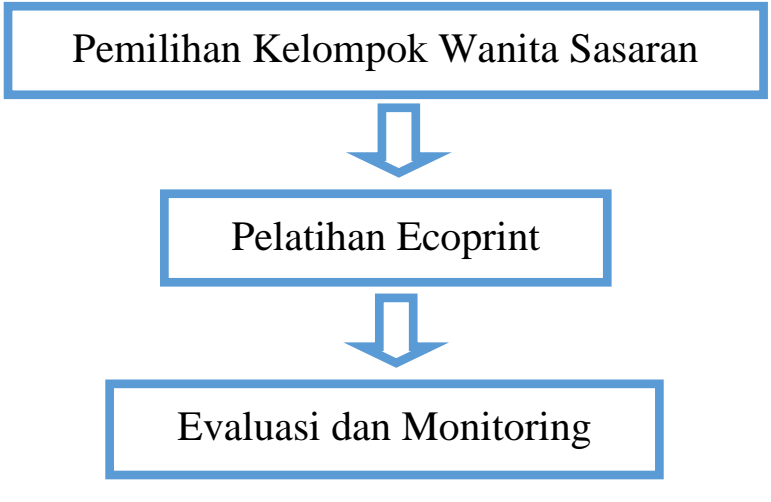

Gambar 1. Tahapan Pelaksanaan

Penjelasan ketiga tahap adalah sebagai berikut,

1. Tahap Pemilihan Kelompok Sasaran

Pengabdian masyarakat yang Dilakukan PSW Unika Soegijapranata ini bertujuan menjadikan perempuan sebagai agen perubahan dalam hal pelestarian lingkungan. Oleh karena itu tahap pertama adalah memilih kelompok sasaran yang tepat. Sebagai calon agen perubahan kami mensyaratkan perempuan yang memiliki: jaringan yang kuat, 
biasa bersosialisasi dan berorganisasi serta memiliki Social Media yang aktif. Soaial media yang disyaratkan adalah Instragram, Facebook dan WhatsApp. Kegiatan pemilihan peserta dilakukan bersama dengan Dinas Pemberdayaan Perempuan dan Perlindungan Anak (DP3A) Kota Semarang. Pada dinas tersebut terkoordinir beberapa komunitas perempuan, Antara lain PKK, GOW dan lain lain. Berdasarkan arahan Kabid PKHP dan Keluarga. kegiatan pengabdian ini dianjurkan untuk ditujukan kepada Gabungan Organisasi Wanita Kota Semarang. Gabungan Organisasi Wanita (GOW) merupakan wadah organisasi perempuan yang mandiri. demokratis, dan bertanggung jawab memperjuangkan terwujudnya pendidikan, kesejahteraan, ekonomi sejalan dengan peningkatan kualitas perempuan. Gabungan Organisasi Wanita Kota Semarang berdiri pada 17 Oktober 1961. GOW adalah sebagai wadah tunggal Organisasi Wanita Kota Semarang, (Titissari, 2016). Berikut ini tabel organisasi yang mengikuti kegiatan sosialisasi peduli lingkungan disertai jumlah anggotanya. Masing masing organisai hanya diwakili oleh satu orang, sehingga total peserta kegiatan sosialisai

Tabel 1. Daftar peserta sosialisasi

\begin{tabular}{|c|l|c|}
\hline No & Organisai Asal (anggota GOW) & Jumlah anggota (orang) \\
\hline 1 & Persatuan Wanita Republik Indonesia (PERWARI) & $>100$ \\
\hline 2 & Persatuan Wanita Kristen Indonesia (PWKI) & 130 \\
\hline 3 & Muslimat NU Kota Semarang & 25.000 \\
\hline 4 & Kerta Wredatama Kota Semarang & 80 \\
\hline 5 & GOW / WKRI & 350 \\
\hline 6 & WSP & $>50$ \\
\hline 7 & IWAPI & 60 \\
\hline 8 & YPSMI / GOW & 35 \\
\hline 9 & Wanita Hindu Dharma Indonesia (WHDI) & 250 \\
\hline 10 & Ikatan Bidan Indonesia (IBI) & 900 \\
\hline 11 & Wanita Islam & 5 \\
\hline 12 & PWN & 40 \\
\hline 13 & Persatuan Istri Purnawirawan (PERIP) & 30 \\
\hline 14 & Organisasi Pensiunan TNI dan Janda (PEPABRI) & 20 \\
\hline 15 & Perwita Wana Kencana & 75 \\
\hline 16 & Persatuan Istri Prajurit TNI-AD (PERSIT) & 400 \\
\hline 17 & Harpi Melati & 200 \\
\hline 18 & Ikatan Istri Dokter Indonesai (IIDI) & 50 \\
\hline 19 & Aisyiyah & $>25.000$ \\
\hline 20 & HWK & 75 \\
\hline 21 & Organisasi Istri Veteran (PIVERI) & 50 \\
\hline
\end{tabular}

Sumber : data primer yang diolah, 2020

\section{Workshop Ecoprint}

Workshop Ecoprint merupakan kegiatan inti dari pengabdian in, dimana peserta seacra aktif ikut membuat tekstil dengan corak Ecoprint. Teknik ecoprint diartikan sebagai suatu proses transfer warna dan bentuk ke suatu media kain melalui kontak secara langsung. Tanaman yang memiliki pigmen warna tertentu ditempelkan ke atas kain yang selanjutnya melalui proses perebusan (Di, Iv, Saptutyningsih, Titis, \& Wardani, 2017). Jenis tanaman yang bisa dijadikan pewarna alami adalah tanaman yang memiliki aroma yang tajam (Husna, 2016). Tanaman dengan aroma yang tajam cenderung memiliki senyawa yang mudah menguap, sehingga bersifat larut air dan menjadi mudah mengeluarkan warna bila direndam. Secara kimia, prinsip yang digunakan dalam tenik ecoprint merupakan prinsip ekstraksi bahan alam, yaitu pemisahan zat berdasarkan perbedaan kelarutan dengan mengambil zat warna dari tanaman, sehingga tanaman yang digunakan merupakan tanaman yang memiliki tingkat 
sensitivitas yang tinggi terhadap panas. Pelaksanaan pelatihan Ecoprint dilakukan bekerjasama sama dengan pengrain batik professional (Batik Warna Alam Si Putri) untuk mendapatkan materi serta sharing terbaik dari praktisi.

\section{Evaluasi dan Monitoring Kegiatan.}

Evaluasi dan Monitoring dilakukan secara bertahap. Kegiatan Evaluasi dan Monitoring perlu dilakukan agar tujuan kegiatan pengabdian ini dapat terlaksana dengan baik dan sesudah pelatihan kegiatan belajar serta penyebarlasan pengetahuan tentang Green Produk dan lingkungan dapat terus berlangsung. Tahap tahap evaluasi dan monitoring adalah sebagai berikut

1) Evaluasi dan Monitoring selama kegiatan pelatihan berlangsung, pada tahap ini peserta di observasi untuk dilihat kemampuannya dalam membuat produk dimulai dari proses pembuatan ecoprint dengan benar dan penilaian terhadap tekstil ecoprint yang dihasilkan.

2) Evaluasi dengan menggunakan Kuesioner. Kuesioner untuk mengukur peningkatan pemahaman peserta diukur dengan menggunakan alat kuesioner pengetahuan responden dan dampak kegiatan yang dibagikan setelah kegiatan berlangsung. Kuesioner berisi jawaban ya dan tidak, sehingga peserta diminta untuk melingkari jawaban yang sesuai. Kuesioner juga berisi data diri peserta serta kesan responden setelah mengikuti kegiatan workshop

3) Monitoring setelah Kegiatan selesai dilakukan. Perkembangan pengetahuan dan penyebaran pengetahuan tersebut diobservasi dari komunikasi yang terjadi pada Whatsapp Group. Selain itu juga dilakukan pengamatan terhadap media social peserta pelatihan terutama Instagram dan facebook mereka. Pengamatan dan interview dalam tahap ini dilakukan selama kurang lebih 1 bulan sesudah acara workshop dilakukan.

\section{HASIL KARYA UTAMA DAN PEMBAHASAN}

Secara keseluruhan kegiatan pengabdian pengenalan Ecoprint sejak tahap awal (analisis permasalahan) dapat dilihat dalam tabel di bawah ini.

Tabel 2. Kegiatan Sosialisasi Perempuan sebagai Agen Perubahan Lingkungan

\begin{tabular}{|c|l|l|l|}
\hline No. & \multicolumn{1}{|c|}{ Kegiatan } & \multicolumn{1}{c|}{ Metode } & \multicolumn{1}{c|}{ Keterangan } \\
\hline 1 & Analisis Masalah & Diskusi & $\begin{array}{l}\text { dilakukan analisis terhadap peningkatan } \\
\text { peran perempuan terhadap kelestarian } \\
\text { lingkungan hidup. Analisis dilakukan oleh } \\
\text { Tim PSW Unika Soegiapranata }\end{array}$ \\
\hline 2 & $\begin{array}{l}\text { Penjajagan Mitra } \\
\text { Pengabdian (Pemilihan } \\
\text { mitra dampingan) }\end{array}$ & Diskusi (FGD) & $\begin{array}{l}\text { Penjajagan Mitra Pengabdian dilakukan } \\
\text { dengan Dinas Pemberdayaan Perempuan } \\
\text { dan Perlindungan Anak (DP3A) Kota } \\
\text { Semarang. Pada dinas tersebut terkoordinir } \\
\text { beberapa komunitas perempuan, Antara lain } \\
\text { PKK, GOW dan lain lain. Berdasarkan } \\
\text { arahan Kabid PKHP dan Keluarga. }\end{array}$ \\
& $\begin{aligned} \text { kegiatan pengabdian ini dianjurkan untuk } \\
\text { ditujukan kepada Gabungan Organisasi } \\
\text { wanita Kota Semarang }\end{aligned}$ \\
& $\begin{array}{l}\text { Pencarian dan penajagan } \\
\text { dengan Mitra Perusahaan } \\
\text { Swasta dan UKM }\end{array}$ & $\begin{array}{l}\text { Komunikasi Formal } \\
\text { dan Informal }\end{array}$ & $\begin{array}{l}\text { dilakukan pencarian dan penajagan } \\
\text { kerjasama dengan beberapa perusahaan } \\
\text { yang memiliki kegiatan CSR yang } \\
\text { berhubungan dengan lingkungan hidup dan } \\
\text { perempuan. Upaya penjajagan menemukan } \\
\text { perusahaan Restoran Cepat saji Hoka Hoka } \\
\text { Bento yang memiliki Visi yang sama } \\
\text { dalam hal upaya pelestarian lingkungan }\end{array}$ \\
& & &
\end{tabular}


PEDULI: Jurnal Ilmiah Pengabdian Pada Masyarakat, 2020, Vol.4, No.1

ISSN: 25974653. EISSN:25974688

http://peduli.wisnuwardhana.ac.id/index.php/peduli/index

\begin{tabular}{|c|l|l|l|}
\hline & & & hidup. \\
\hline 4 & $\begin{array}{l}\text { Persiapan Worshop dan } \\
\text { koordinasi dengan lembaga } \\
\text { mitra }\end{array}$ & $\begin{array}{l}\text { Survey tempat dan } \\
\text { lokasi pelatihan }\end{array}$ & $\begin{array}{l}\text { persiapan materi, sarana dan prasara serta } \\
\text { tata ruang. Persiapan ini dilakukan Tim } \\
\text { PSW, CSR dan Trainer (Batik Warna Alam } \\
\text { SiPutri) }\end{array}$ \\
\hline 5 & Pelaksanaan Workshop & $\begin{array}{l}\text { Pelatihan pembuatan } \\
\text { Ecoprint }\end{array}$ & $\begin{array}{l}\text { Mulai dari pembukaan dan pelatihan } \\
\text { dengan praktek langsung. Metode yang } \\
\text { digunakan adalah Pounding }\end{array}$ \\
\hline 6 & $\begin{array}{l}\text { Keberlanjutan } \\
\text { Pemeliharaan pengetahuan } \\
\text { ketrampilan dan upaya } \\
\text { penyebarluasan }\end{array}$ & $\begin{array}{l}\text { Komunikasi evaluasi } \\
\text { dan perkembangan } \\
\text { melalui Whach App } \\
\text { Group }\end{array}$ & $\begin{array}{l}\text { Pada tahap ini para peserta di eavluasi } \\
\text { dalam kelanjutan kreativitasnya dalam } \\
\text { pembuatan kain ecoprint. Apakah ada upaya } \\
\text { untuk membuat produk lain selain yang } \\
\text { dihasilkan saat ini. Serta Upaya penyebaran } \\
\text { pengetahuan tentang Ecoprint }\end{array}$ \\
\hline
\end{tabular}

Hasil dan Luaran dari kegiatan pengabdian adalah sebagai berikut.

\section{Peningkatan Ketrampilan Pembuatan Produk Ramah Lingkungan (Tekstil Ecoprint)}

Salah satu tahap menjadikan perempuan sebagai agen peduli lingkungan hidup adalah dengan memberikan ketrampilan membuat satu produk yang ramah lingkungan. Peningkatan kemampuan membuat produk ramah lingkungan dapat digunakan sebagai sarana penyebar luasan peduli lingkungan kepada masyarakat luas. Pelatihan pembuatan Produk hijau (Ecoprint) dipilih karena hasilnya menarik, pembuatannya mudah, hasil produknya dapat digunakan sebagai produk fasion (baju, hijab dan lain lain). Produk yang menarik diharapkan akan menarik perhatian pihak lain untuk memakai atau mempelajari untuk membuatnya. Dengan kata lain produk Ecoprint diharapkan akan menjadi trigre bagi pihak lain untuk perduli lingkungan. Dengan kriteria ini maka diharapkan pengusaan ketrampilan pembuatan produk ecoprint akan dapat membantu kegiatan perempuan sebagai agen peduli lingkungan.

Seluruh peserta berhasil membuat tekstil yang ramah lingkungan dengan metode Ecoprint. Berikut Foto keseluruhan peserta, tim pengabdi, dan tainer beserta dengan hasil karyanya. Berikut ini beberapa foto kegiatan workshop tersebut.

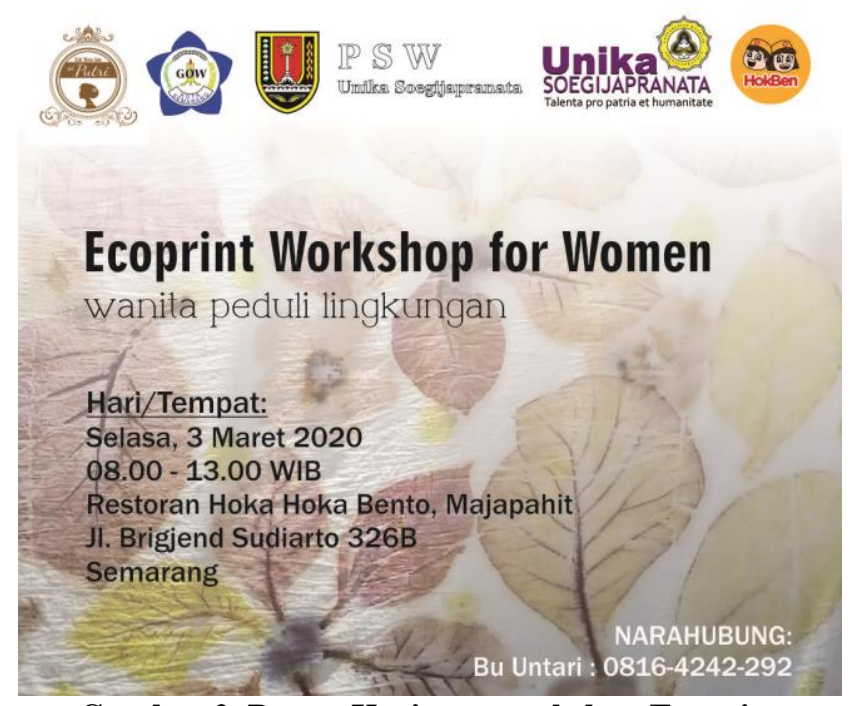

Gambar 2. Poster Kegiatan workshop Ecoprint 


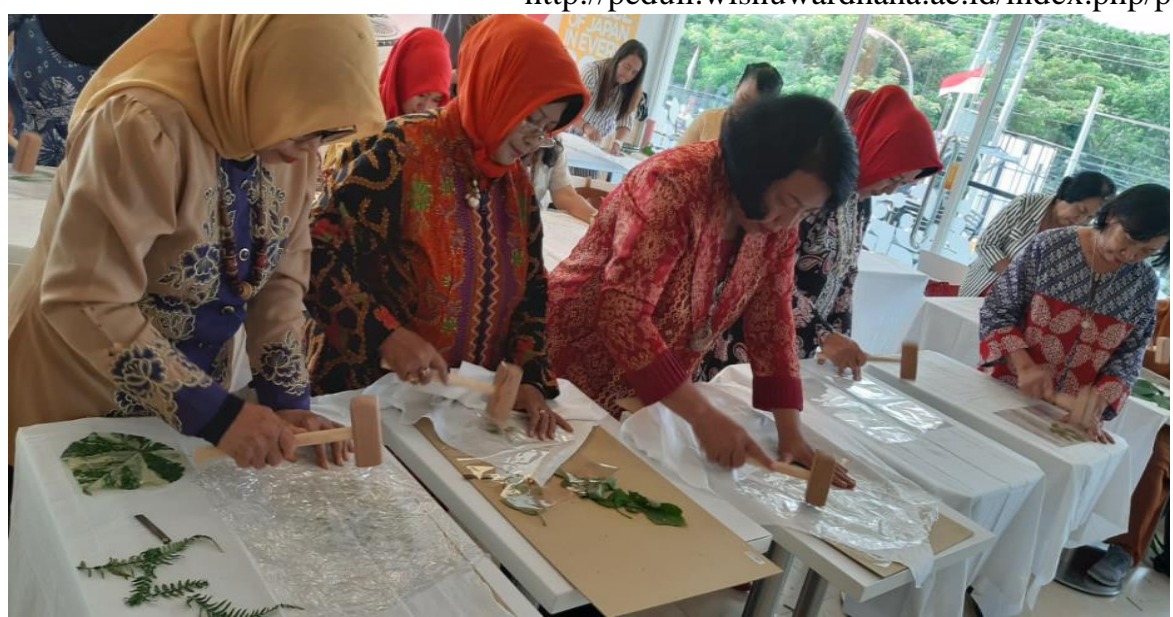

Gambar 3. Peserta sedang berlatih membuat Ecoprint

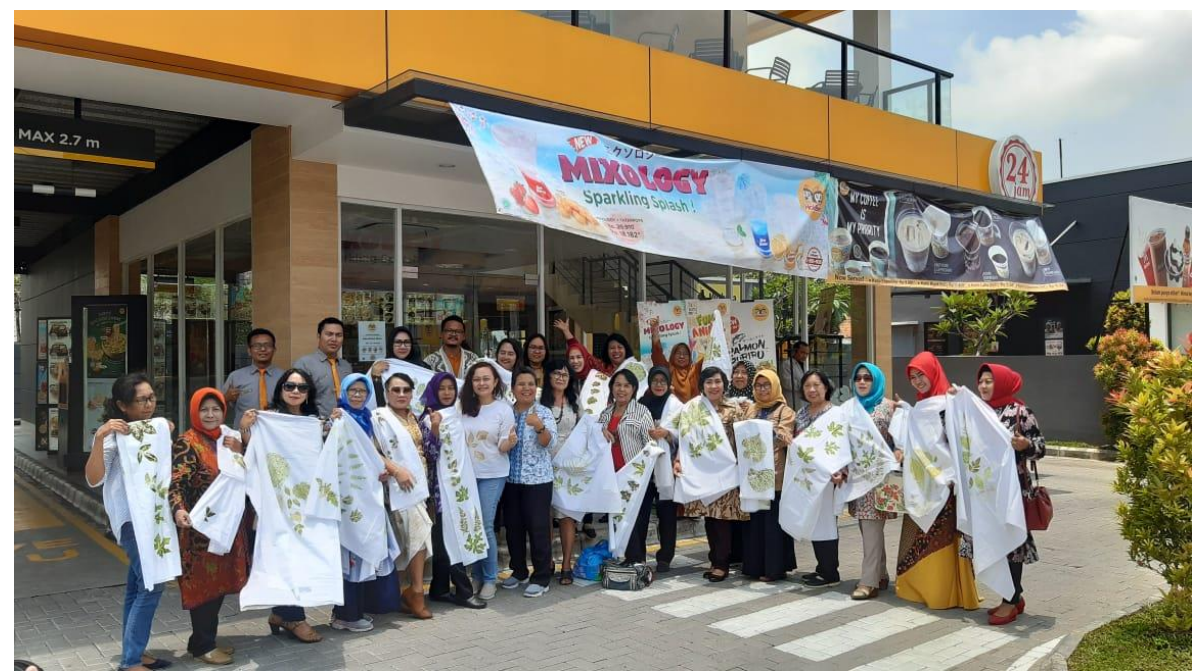

Gambar 4. Peserta beserta hasil karyanya

\section{Kesediaan Membeli /Memilih Produk Ramah Lingkungan untuk Kehidupan Sehari hari}

Kesediaan membeli atau memilih produk ramah lingkungan menjadi salah satu modal bagi seorang perempuan menjadi agen peduli lingkungan. Hal ini karena pilihan atas produk yang dipakai seorang agen berarti menjadi contoh bagi pihak lain yang diharapkan akan tertarik memakai produk yang ramah lingkungan.

Sebelumnya akan disampaikan kondisi pengetahuan para perempuan peserta pelatihan (sebelum mengikuti peatihan). Pertama pengetahuan peserta tentang Ecoprint dapat digambarkan dalam grafik berikut ini 


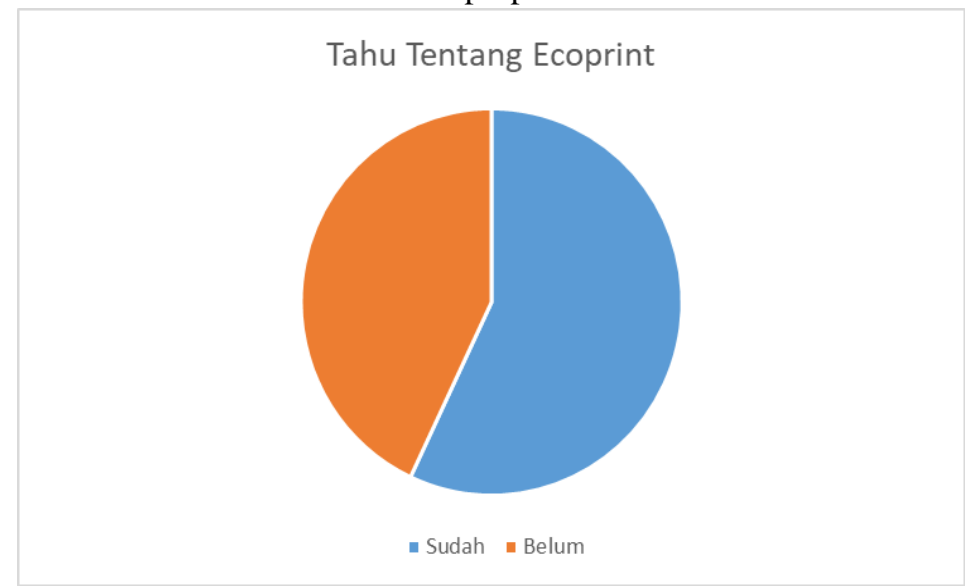

Gambar 5. Pengetahuan tentang Ecoprint

Gambar diatas menjelaskan bahwa sebenarnya Ecoprint bukan hal yang sama sekali baru bagi peserta pelatihan. Sebagian besar belum tahu (57\%) sebagian kecil (43\%) sudah tahu tentang Ecoprint. Namun demikian belum ada yang tahu cara membuat Ecoprint.

Sementara gambar dibawah ini menunjukan hasil kuesioner yang bahwa sebagian besar dari peserta sosialisasi belummenggunakan warna alam untuk tekstil atau pakaianan yang digunakan untuk dirinya sendiri maupn keluarganya.

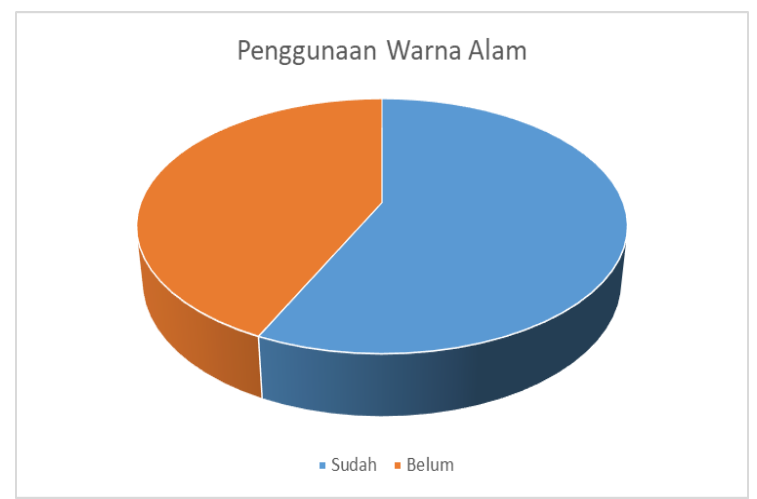

Gambar 6. Penggunaan tekstil warna alam

Selanjutnya tentang kesediaan seluruh peserta workshop terhadap keberlanjutan kegiatan peduli lingkungan dapat disampaiakan sebagai berikut :

1) Akan mebuat kain dengan motiv ecoprint

2) Bersedia menggunakan kain Ecoprint yang dihasilkan dari pelatihan sebagai busananya

3) Bersedia menyebarluaskan pengretahuannya tentang Ecoprint melalui media social yang dimiliki, menyebarluaskan kepada keluarga, dan menyebarluaskan kepada anggota Organisasi yang diwakilinya.

4) Bersedia menggunakan produk lain (diluar tekstil) yang ramah lingkungan.

\section{Penyebarluasan Pengetahuan Produk Ramah Lingkungan}

Salah satu peran wanita adalah dalam pelestarian lingkungan hidup menjadi agen perubahan dengan cara menyebarluaskan pengetahuannya kepada keluarga ataupun masyarakat sekitarnya. Setelah kegiatan pelatihan ecoprint ini potensi penyebar luasan dapat dilihat dar hasil kuesioner dimana $100 \%$ menyatakan ingin menyebarluaskan. Jika dianalisa lebih lanjut anggota organisasi memiliki kesempatan luas untuk 
menyebarluaskan di kalangan sesama organisasi asalnya. Rata rata jumlah anggota organisasi asal adalah 100 orang.

Penyebarluasan pengetahuan produk Hijau berupa Ecoprint ini juga dilakukan melalui media social yang dimiliki peserta. Semua peserta memili akun social media. Mereka menggunakannya secara aktif dengan follower diatas 200. Social Media yang digunakan Instragram, Facebook dan WhatsApp. Selain itu juga ada social media kelompok masing masing dan juga GOW. Pada saat pelatihan juga dilakukan upload akonten ke instragram secara bersama sama dengan hastag tertentu. Dengan demikian teradi penyebaran informasi tentang Ecoprint sebagai contoh dari Green product.

Penyebaran informasi yang berikutnya dapat diobservasi dari perkembangan yang terlihat di dalam Whatsapp Group. Berdasarkan Observasi di Wa Group ditemukan bahwa:

1) Terjadi pemesanan peralatan (palu) oleh beberapa peserta. Hal ini menunjukkan peserta masih ingin melanjutkan atau membuat lagi tekstil ecoprint. Bahkan sebagian peserta membeli lagi (dari trainer) satu paket bahan (kain, palu dan bahan pengunci)

2) Terjadi pemesanan bahan secara kolektif oleh Organisasi asal peserta dalam hal ini Organisasi IDII (ikatan Istri Dokter Indonesia). Menurut Ibu Lely yang saat itu menadi peserta wakil IDII menyatakan bahwa setelah melihat foto fotonya dan bertanya, anggota IDII ingin mengikuti membuat Ecoprint secara beramai ramai.

3) Peserta secara sungguh sungguh ingin menggunakan kain hasil karya mereka untuk acara penting merika misalnya Perayaan Paskah.

\section{KESIMPULAN}

Perempuan memiliki potensi yang besar sebagai agen perubahan dalam gerakan peduli lingkungan. Agar calon agen peduli lingkungan dapat melaksanakan kesanggupannya dengan baik, maka perlu dipilih para calon agen yang memiliki potensi. Kriterianya adalah memiliki networking yang kuat salah satu contong networking yang kuat adalah aktif dalam berorganisasi. Syarat kedua perempuan calon agen perubahan/peduli lingkungan tersebut juga harus aktif di media sosial, terutama media sosial yang sedang populer (banyak pengikutnya) seperti Istagram dan Facebook.

Salah satu cara melakukan sosialisasi adalah workshop atau pelatihan. Dalam hal sosialisasi Agen Peduli lingkungan maka perlu dipilih workshop yang menarik, yaitu mudah dibuat (dikerjakan) oleh peserta pelatihan, hasilnya bagus sehingga menarik untuk dilihat dan ditiru pihak lain. Mudah untuk replikasi ulang, sehingga peserta pelatihan dapat segera menjadi pelatih bagi pihak lain. Dalam kegiatan Sosialisasi Agen Peduli Lingkungan ini, Workshop Ecoprint dianggap berhasil menjadi media pelatihan yang menarik dan berhasil. Keberhasilan kegiatan sosialisasi yang bertujuan untuk menumbuhkan agen perubahan tergantung pada pemilihan mitra binaan, metode sosialisasi dan pembinaan setelahnya (tidak hanya pelatihan sesaat). Perlu dilakukan penelitian lebih lanjut tentang peran sosial media yang dimiliki perempuan dalam upaya penyebarluasan.

\section{UCAPAN TERIMAKASIH}

1. Dinas Pemberdayaan Perempuan dan Perlindungan Anak (DP3A) Kota Semarang

2. Gabungan Organisasi Wanita Semarang

3. Restoran Cepat saji Hoka Hoka Bento Cabang Majapahit Semarang dan Pusat Jakarta

4. Batik Warna Alam Si Putri

5. LPPM Unika Soegijapranata

6. Seluruh tim Pengabdian PSW Unika Soegijapranata 


\section{DAFTAR PUSTAKA}

Di, E., Iv, D., Saptutyningsih, E., Titis, D., \& Wardani, K. (2017). Pemanfaatan Bahan Alami Untuk Pengembangan Produk, 9.

Husna, F. (2016). Eksplorasi Teknik Eco Dyeing Dengan Memanfaatkan Tanaman Sebagai Pewarna Alam Untuk Produk Lifestyle. Journal of Chemical Information and Modeling, 3(2), 1-27. https://doi.org/10.1017/CBO9781107415324.004

Mahour, K. (2016). Role of Women in Environment Conservation. Journal of Advanced Laboratory Research in Biology, 7(1), 17-26.

Titissari, D. N. (2016). Peran gabungan organisasi wanita (gow) dalam meningkatkan keterampilan anggota di kota semarang skripsi.

UNEP. (2015). Gender and the Environment Historical Background, (March), 1-4. Retrieved from http://www.unep.org/gender/data/AboutUs/HistoricalBackground/tabid/54774/Def ault.aspx

UNIDO. (2015). Guide on gender mainstreaming environmental management projects. 